\title{
EXAMINATION OF VIRTUAL PHANTOMS WITH RESPECT TO THEIR POSSIBLE USE IN ASSESSING COMPLIANCE WITH THE ELECTROMAGNETIC FIELD EXPOSURE LIMITS SPECIFIED BY DIRECTIVE 2013/35/EU
}

\author{
PATRYK ZRADZIŃSKI
}

\section{Central Institute for Labour Protection - National Research Institute, Warszawa, Poland}

Laboratory of Electromagnetic Hazards

\begin{abstract}
According to Directive 2013/35/EU, any assessment of hazards associated with exposure to electromagnetic fields (EMF) in the workplace needs an evaluation of quantities characterizing biophysical effects caused inside human bodies by exposure. Such quantities (induced electric field or specific energy absorption rate) may be evaluated by computer simulations in virtual models (phantoms), representing interaction between EMF and the worker's body with respect to modelling the EMF source, the structure of the working environment and the human body. The paper describes the effects of the properties of various virtual phantoms used in recently published studies on various aspects of EMF exposure with respect to their possible involvement in assessing occupational electromagnetic hazards as required by Directive 2013/35/ EU. The parameters of phantoms have been discussed with reference to: dimensions, posture, spatial resolution and electric contact with the ground. Such parameters should be considered and specified, and perhaps also standardized, in order to ensure that the numerical simulations yield reliable results in a compliance analysis against exposure limits or in an exposure assessment for EMF-related epidemiological studies. The outcomes of the presented examination of virtual phantoms used in numerical simulations show that they can be effectively used in the assessment of compliance with the exposure limits specified by Directive 2013/35/EU, but various other factors should be also considered, e.g., the relationship between phantom posture and a realistic exposure situation (flexible phantoms use), limited resolution preventing reliable evaluation of physical estimators of exposure, or a non-realistic area of phantom surface in contact with the ground.
\end{abstract}

Key words:

Electromagnetic field, Numerical simulations, Human body virtual phantom, Specific energy absorption rate, Induced electric field

Research task (04.A.02) carried out within the scope of the second stage of the National Programme "Improvement of safety and working conditions" partly supported in 2011-2013 - within the scope of state services - by the Ministry of Labour and Social Policy. The Central Institute for Labour Protection - National Research Institute is the Programme's main co-ordinator. Project manager: Patryk Zradziński, Ph.D.

Received: May 29, 2014. Accepted: January 6, 2015.

Corresponding author: P. Zradziński, Central Institute for Labour Protection - National Research Institute, Laboratory of Electromagnetic Hazards, Czerniakowska 16, 00-701 Warszawa, Poland (e-mail: pazra@ciop.pl). 


\section{INTRODUCTION}

Exposure to electromagnetic fields (EMF) causes various biophysical effects, which include: vertigo and nausea, impaired blood flow, nerve, muscle or cardiac excitation, and a localised or whole-body rise in temperature [1-3]. The levels of physical estimators of various exposure effects depend mainly on the shape, posture, bioelectric and biophysical properties of the exposed body, and on the frequency, spatial distribution and strength of incident EMF. New European Directive 2013/35/EU specifies exposure limits based on international guidelines and oblige employers to assess exposure levels in order to make sure that the workplace complies with the provisions of the directive $[2,4,5]$.

The induced electric field and absorbed EMF energy are also used to assess exposure in EMF-related epidemiological studies, e.g., of cancer risk among mobile phone users. The general public is usually exposed to weak EMF when human body is far from an EMF source (and exposure can be assumed to represent exposure to weak EMF plane wave homogenous in space, e.g., from RTV broadcasting antenna) $[6,7]$ or when it is in the vicinity of a localised relatively weak EMF source (e.g., mobile phone handset antenna) [8,9]. On the other hand, workers may be present in the vicinity of localised sources of relatively strong EMF, and in some cases the worker's torso or limbs may even touch them; it is therefore likely that such exposure can cause significant effects in the body [10]. In general, high-exposed groups include industrial workers and healthcare personnel operating EMF sources from a short distance, e.g., induction heaters, plastic sealers, welding devices, physiotherapic diathermy or electrosurgery devices [11].

According to Directive 2013/35/EU [5], in the case of "a very localised source within a distance of a few centimetres from the body, compliance with exposure limit values shall be determined dosimetrically (e.g., by numerical simulations), case by case." The physical estimators (exposure limit values) set out in the directive are "based on the recommendations of the International Commission on
Non-Ionizing Radiation Protection (ICNIRP) and should be considered in accordance with ICNIRP concepts, save where this Directive specifies otherwise" [2,3,5]. Investigations carried out by Jokela et al. respecting ICNIRP guidelines show that such an approach is needed for very localised sources closer than $20 \mathrm{~cm}$ to the body [3,12].

The author's investigations show differences between physical estimator values in standing and sitting phantoms of up to 36 times; differences between grounded and insulated phantoms of up to 12 times; and differences between anatomical phantoms and homogenous simple shape phantoms (cylindrical) of up to 4 times [13].

\section{THE KEY PROVISIONS CONCERNING THE USE OF NUMERICAL SIMULATIONS IN EMF EXPOSURE EVALUATIONS}

Electric field induced in the body $\left(\mathrm{E}_{\mathrm{in}}\right)$ and specific energy absorption rate (SAR) are assessed by numerical simulations (or computer modelling) in order to test compliance with Directive 2013/35/EU exposure limits.

The limits of induced electric field $\left(\mathrm{E}_{\mathrm{in}}\right)$ are provided by the directive up to $10 \mathrm{MHz}$, in compliance with ICNIRP 2010 guidelines [3,5]. Those exposure limits refer to EMF exposure effects in the central nervous system (CNS), in the head or in all other tissues throughout the whole body.

The limits of SAR are provided by the directive for an EMF exposure with a frequency ranging from $100 \mathrm{kHz}$ to $10 \mathrm{GHz}$, in compliance with ICNIRP 1998 guidelines [2]. The exposure limits refer to excessive temperature rises in the body and concern the whole body average (WBA) SAR, or localised SAR in the head, trunk and limbs.

\section{THE KEY PRINCIPLES OF NUMERICAL MODELING OF THE HUMAN BODY FOR EMF EXPOSURE ASSESSMENTS}

Various shapes and dimensions representing workers' bodies are the 1st property of virtual models (phantoms) used in numerical simulations. For example, 
Table 1. Height of Polish, Norwegian, Portuguese populations and reference values by International Commission on Radiological Protection (ICRP)

\begin{tabular}{lcccccccc}
\hline & \multicolumn{9}{c}{$\begin{array}{c}\text { Height } \\
\text { [cm] }\end{array}$} \\
\cline { 2 - 9 } & Percentile & \multicolumn{2}{c}{ Polish [14] } & \multicolumn{1}{c}{ Norwegian [15] } & \multicolumn{2}{c}{ Portuguese [15] } & \multicolumn{2}{c}{ ICRP [16] } \\
\cline { 2 - 9 } & male & female & male & female & male & female & male & female \\
\hline 5 th & 164 & 152 & 169 & 156 & - & - & - & - \\
50 th & 175 & 162 & 180 & 166 & 172 & 160 & 176 & 163 \\
95 th & 185 & 171 & 190 & 176 & - & - & - & - \\
\hline
\end{tabular}

the 50th percentile of height of particular European populations - Polish, Norwegian, Portuguese - ranges from 160 to $166 \mathrm{~cm}$ for females, and from $172 \mathrm{up}$ to $180 \mathrm{~cm}$ for males (Table 1) [14,15]. Likewise, the heights of International Commission on Radiological Protection (ICRP) reference phantoms of the European population are $163 \mathrm{~cm}$ for females and $176 \mathrm{~cm}$ for males [16], and were used in the process of developing various anatomical virtual phantoms. As a result, such phantoms do not match the dimensions of lower and higher percentiles of populations.

Human body phantoms used in numerical calculations consist of huge numbers of cuboids (called voxels) or tetrahedrons (called finite elements). The dimensions of such solids are phantom resolution, which is one of the most important parameters of phantoms, because $\mathrm{E}_{\text {in }}$ and SAR values should be averaged over specified masses or volumes: $\mathrm{E}_{\text {in }}$ should be the 99th percentile value averaged over any volume of $2 \times 2 \times 2 \mathrm{~mm}^{3}$ contiguous tissue (ICNIRP 2010), and localised SAR should be averaged over a continuous mass of $10 \mathrm{~g}$ (Directive 2013/35/ EU, ICNIRP 1998) [2,3,5].

The most frequently used dielectric properties of particular tissues and organs (relative permittivity $-\varepsilon_{\mathrm{r}}$, electric conductivity $-\sigma$ ) were taken from the set of experimentally determined data [17]. In the case of using a homogenous phantom, the values of both electrical parameters are constant in the phantom and usually refer to the parameters of muscle. Heterogeneous phantoms typically consist of tens of tissues or organs of various dielectric properties, e.g., for an EMF frequency of $27 \mathrm{MHz}$ (900 MHz):

- muscle $-\varepsilon_{\mathrm{r}}=95.95(55.03)$ and $\sigma=0.654(0.942) \mathrm{S} / \mathrm{m}$;

- brain grey matter $-\varepsilon_{\mathrm{r}}=163.83 \quad(52.73)$ and $\sigma=0.412(0.942) \mathrm{S} / \mathrm{m}$;

- fat $-\varepsilon_{\mathrm{r}}=8.47(5.46)$ and $\sigma=0.033(0.051) \mathrm{S} / \mathrm{m}$;

- cortical bone $-\varepsilon_{\mathrm{r}}=21.82(12.45)$ and $\sigma=0.052$ (0.143) S/m;

- heart $-\varepsilon_{\mathrm{r}}=159.03(59.89)$ and $\sigma=0.588(1.230) \mathrm{S} / \mathrm{m}$. Another problem of numerical calculations is the worker's body contact with grounded basis $[18,19]$. The calculations most frequently used: the worker is grounded (bare feet touch grounded basis - the worst case scenario of exposure to the E-field) or the worker is insulated (model placed in free space without touching any grounded conductible element). At the real workplace, the worker's body contact with grounded basis is through the sole made of e.g., rubber, which is an intermediate case between grounded and insulated.

Taking into account presented general issues related to the procedures of the use of numerical simulations in the EMF exposure assessment, this paper discusses the usefulness and limitations of virtual phantoms used in recently published investigations in assessments of exposure to EMF by numerical simulations with respect to Directive 2013/35/EU requirements. 


\section{VIRTUAL PHANTOMS USED IN EMF STUDIES}

Fine resolution realistic whole-body voxel phantoms are usually derived from detailed medical imaging data (e.g., 7T magnetic resonance scanners allow images to be made with a resolution of $0.1 \mathrm{~mm}$, and the computed tomography scanners use $1 \mathrm{~mm}$ resolution).

The essential parameters of phantoms used in numerical simulations and their usefulness for an assessment of occupational exposure to EMF are listed in Table 2 and discussed in the following sections.

\section{Simplified phantoms}

The most simplified phantoms - cylindrical, spherical or ellipsoidal - do not adequately represent the human body shape and can only be used for a very rough EMF exposure assessment (e.g., EN 50505:2008 suggests the use of cylindrical and ellipsoidal phantoms of $60 \mathrm{~cm}$ height and $30 \mathrm{~cm}$ diameter corresponding to the dimensions of the torso in magnetic field exposure simulations) [20].

\section{Anatomical posture phantoms}

Block-structured [21] or human-shaped [22] phantoms were also used when more precise exposure evaluation was needed. Likewise, it is recommended (ICNIRP 2010, EN 50505:2008) to use anatomicallybased phantoms with relatively high spatial resolution (e.g., $2 \times 2 \times 2 \mathrm{~mm}^{3}$ ) which can fit internal organs and their electric properties [3,20]. The most popular phantoms used in recently published research results by numerical calculations are male and female phantoms developed by NRPB (National Radiological Protection Board - Health Protection Agency, UK): male NORMAN (normalised man) consisting of 35 tissues [6,23,24], its improved version NORMAN-05 [25], and 23-year-old female phantom NAOMI (aNAtOMIcal model) consisting of 41 tissues [18]. All phantoms were developed with the use of magnetic resonance imaging (MRI) data and comply with ICRP requirements [16].
Other phantoms complying with reference ICRP requirements: male phantom, developed with the use of MRI data at the University of Utah (USA) (30 tissues) [19] and male and female phantoms - Golem (85 tissues) and Laura (89 tissues), developed with the use of computed tomography (CT) data by GSF - National Research Center for Environment and Health (Germany) [26,27].

Japanese male and female phantoms consisting of 51 tissues, developed with the use of MRI data by the Kitasato University Graduate School of Medical Sciences (Japan) from data of average-sized Japanese volunteers [6].

Phantoms created on the basis of the MRI and CT data of 38-year-old male from the Visible Human Project (VHP) [28]:

- The Brooks Digital Anatomical Man (39 tissues), developed as a result of collaboration between the National University of Singapore (Singapore) and Johns Hopkins University (USA) [29];

- VIP-man (1400 structures), developed by the Rensselaer Polytechnic Institute (USA) [30];

- SEMCAD VHPWB-1: Whole Body Adult Male Phantom (100 structures), developed by Schmid \& Partner Engineering AG (Switzerland) for SEMCAD software [31] and HUGO - The Professional Anatomical Data Set (40 tissues), developed by Medical Virtual Reality Studio GmbH, Germany for Computed Simulation Technology (CST, Germany) Studio Suite software [32]. Adult Korean phantoms were developed by the Hanyang University (Korea) [29,33,34]:

- Korean Man (KORMAN) - consisting of 20 tissues; developed using MRI data (above the middle of thighs without forearms and hands) and VHP data (remaining parts of legs);

- Korean Typical Man-1 (KTMAN-1) - consisting of 29 tissues; developed using MRI data (whole body without upper limbs);

- Korean Typical Man-2 (KTMAN-2) - consisting of 29 tissues; developed using CT data (whole body). 
VoxelMan standing and sitting phantoms (68 tissues) were developed using MRI and CT data by the University of Victoria (Canada) on the basis of head and torso of phantoms developed by the Yale School of Medicine (USA) and limbs from VHP data $[24,29,35]$.

Male and female phantoms MAX and FAX (both, 122 tissues) developed using MRI and CT data at Federal University of Pernambuco (Brazil) [36,37]. MAX was created on the basis of the same data as VoxelMan, while FAX was created by merging data from a 37-yearold (torso, upper limbs) and a 62-year-old female (legs) with a scaled MAX head.

High Fidelity Male (23 tissues) and Female (34 tissues) Body Mesh were developed with the use of MRI and CT data by Remcom (USA) for XFdtd software [38].

Bio Models family, consisting of 57 tissues, was developed by CST for CST Studio Suite software [32]. The Bio Models family contains the following phantoms: 38 -year-old male Gustav, 40-year-old female Donna, 26-year-old female Emma, 43-year-old female Laura, 43-year-old pregnant female Katja, 7-year-old girl Child and 2-month-old girl Baby.

All these phantoms are developed as a human body in natural (standing) posture except for VoxelMan which is in the sitting posture.

\section{Anatomical multi-posture phantoms}

More realistically postured phantoms have recently been intensively developed. Examples of such phantoms are Dielectric Anatomical Models developed by the Centre for Scientific and Technological Research (Italy) laboratory using MRI data from a 34-year-old male (mDAM) and a 30-year-old female (fDAM) [7]. Both phantoms allow the body posture to be changed at the knee, elbow and hip joints.

Human body numerical phantom posture change is also possible using VariPose software developed by Remcom [38], which repositions the voxels of the male phantom developed on the basis of VHP data. VariPose allows the repositioning of the main joints, like knee, hip and elbow and down to thumb and finger - while maintaining the continuity of internal structures (especially nerves and blood vessels) and conserving the mass of particular tissues.

Virtual Population phantoms were developed with the use of MRI data by the IT'IS Foundation (Information Technologies in Society Foundation, Switzerland) [39,40]. The Virtual Population family contains 10 phantoms:

- 5 females - Glenn (84-year-old, 84 tissues), Ella (26-year-old, 76 tissues), Billie (11-year-old, 75 tissues), Eartha (8-year-old, 75 tissues), and Roberta (5-year old, 66 tissues);

- 5 males - Fats (37-year-old, 79 tissues), Duke (34-yearold, 77 tissues), Louis (14-year-old, 77 tissues), Dizzy (8-year-old, 66 tissues), and Thelonious (6-year-old, 76 tissues).

A family of homogenous or semi-homogenous phantoms named CIOP-MAN was developed by the Central Institute for Labour Protection - National Research Institute (CIOP-PIB) (Poland) [41,42]. The original phantom was based on data of 50th percentile Polish males with a body height of $175 \mathrm{~cm}$, using basic solids, such as cylinders, spheres, bricks or cones, and slight modifications of those solids (Figure 1) [14]. The CIOP-MAN phantom structure allows the easy resizing of its dimensions. The CIOP-MAN family also includes phantoms of the 5 th and 95th percentile (164 and $185 \mathrm{~cm}$ in height, respectively), created by resizing the original 50th percentile model. Phantoms allow repositioning in the following joints: knee, hip, elbow, neck, ankle and shoulder, which allow a worker's posture while operating an EMF source to be realistically presented. It is also possible to implement different solids in homogenous phantoms in order to represent the structures of the brain, heart or other structures corresponding to the exposure limits under consideration, e.g., the brain in an analysis of 


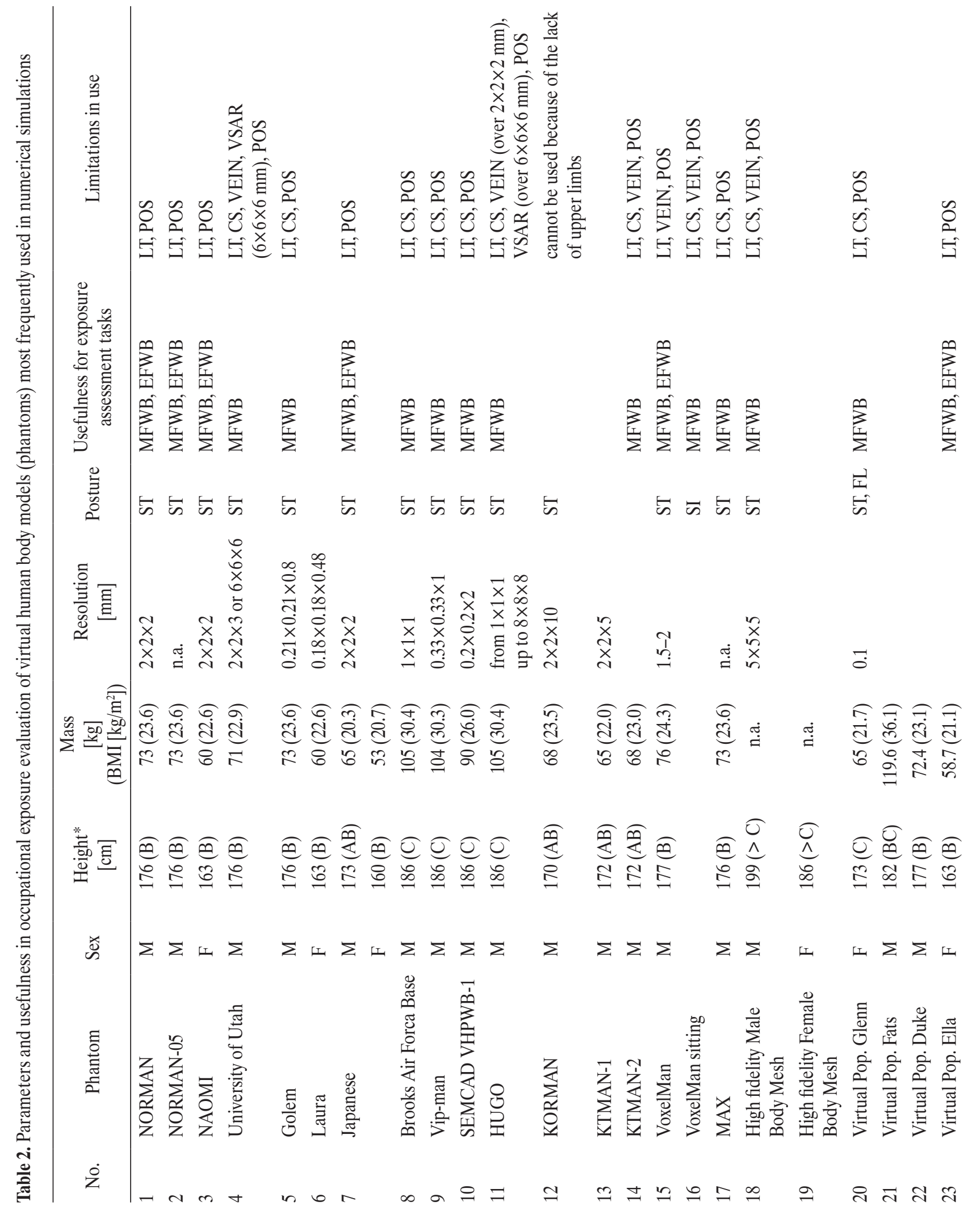



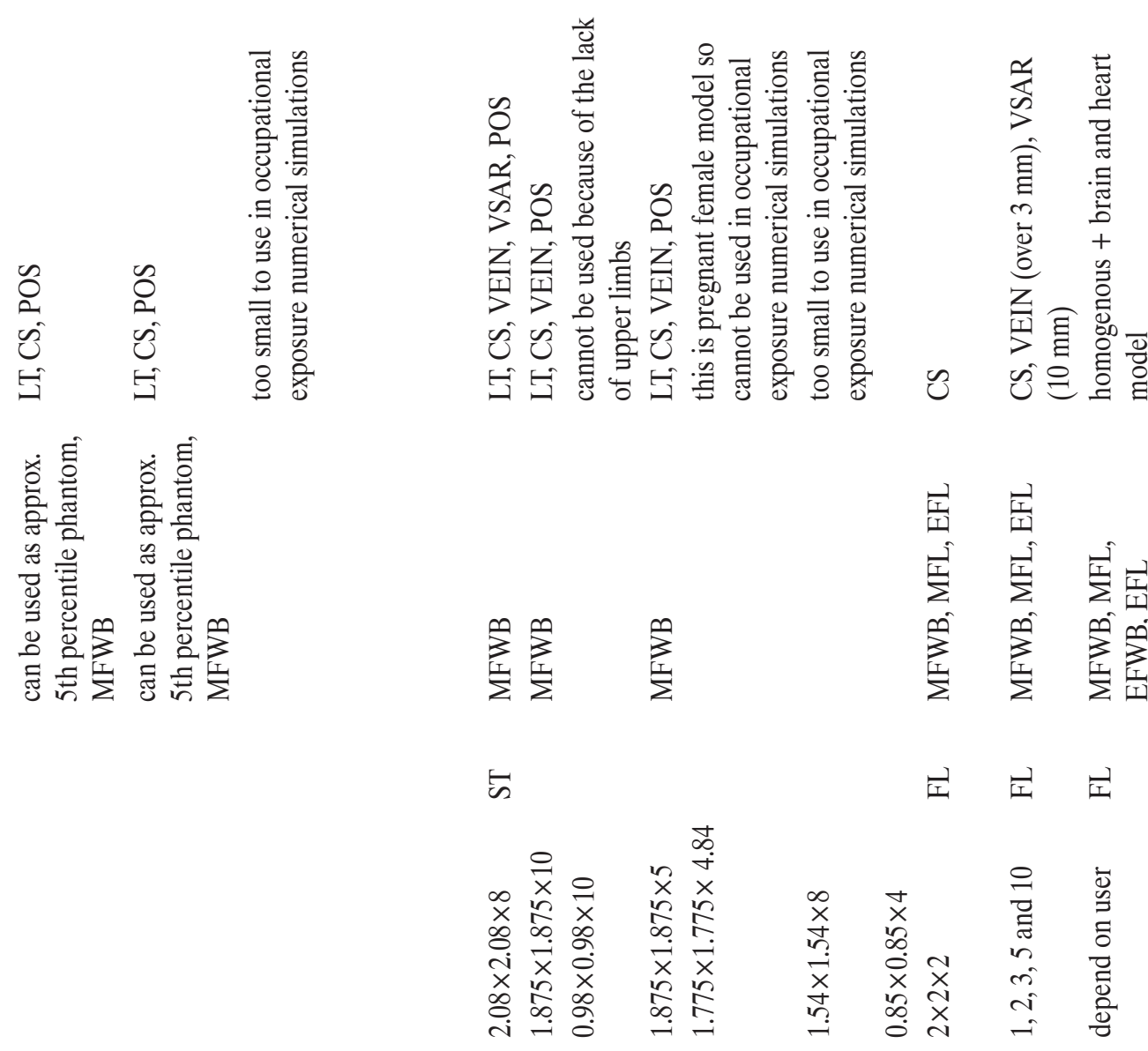

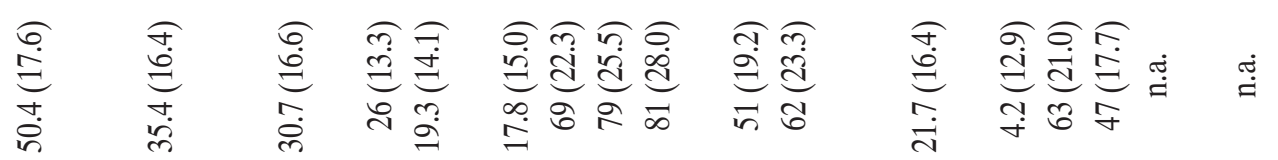

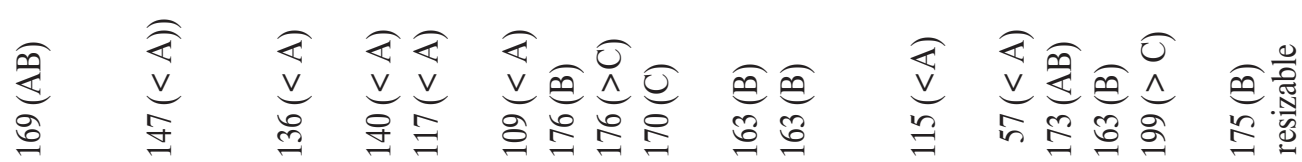

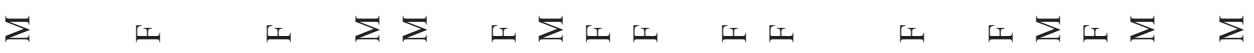

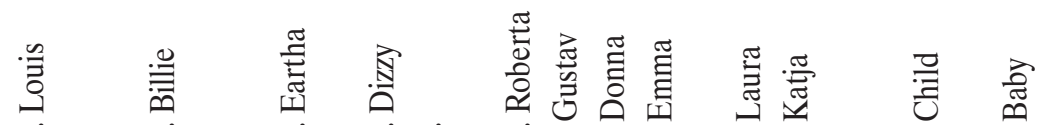

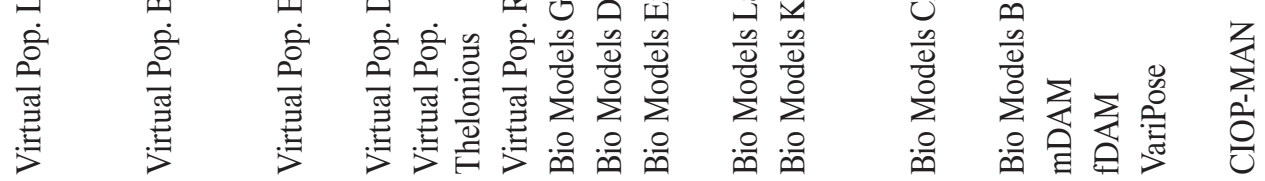

구 


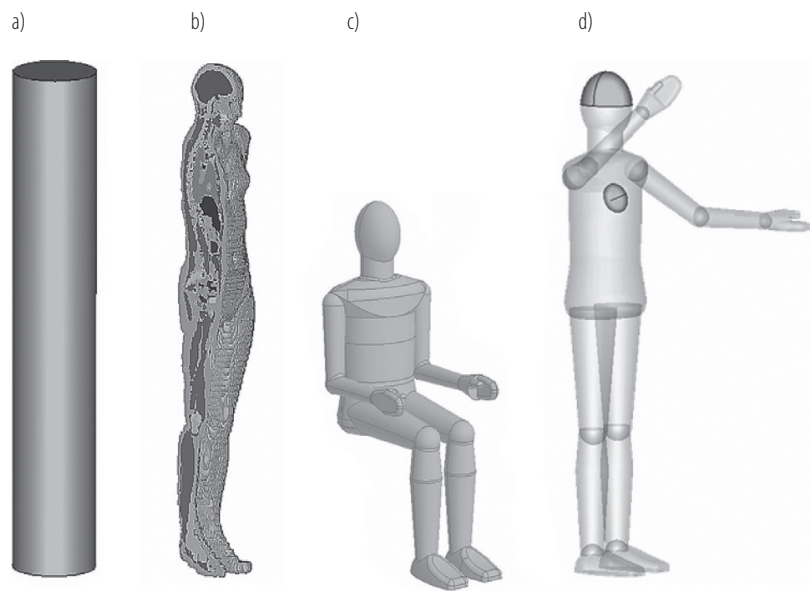

Fig. 1. Virtual phantoms: a) homogenous, cylindrical, b) heterogeneous, anatomical - Laura (CST) - cross-section of internal structures of the phantom created by CST STUDIO software, c) CIOP-MAN representing dimensions of Polish adults - homogenous in sitting posture, and d) CIOP-MAN in standing posture, semi-homogenous with implemented brain and heart shaped structures

compliance with ICNIRP guidelines, or body structures related to investigated end points of epidemiological research.

\section{APPLICABILITY OF HUMAN BODY VIRTUAL PHANTOMS IN AN EVALUATION OF OCCUPATIONAL EXPOSURE TO EMF}

\section{Phantoms used to validate the numerical method}

Anatomically-based virtual phantoms allow simulations to be made of absorbed EMF energy distribution in particular body parts (head/torso/legs). Simple shape phantoms (cylindrical, elliptical or spheroidal) do not adequately represent those parts of the human body, and therefore the values of localised $\mathrm{E}_{\text {in }}$ or SAR can be calculated only to roughly evaluate the exposure of head, torso or legs. Thus, simple shape phantoms are of limited applicability for a precise analysis of EMF hazards. However, these homogenous phantoms are still widely used in the process of validating numerical methods and more complex models used in simulations $[13,20]$.

\section{Dielectric properties of body tissues}

One of the key issues in occupational exposure numerical simulations concerns the frequency dependent dielectric properties of human body tissues. Those parameters have a great impact on $\mathrm{E}_{\text {in }}$ and $\mathrm{SAR}$ values, and their number depends on the physical quantity under evaluation $[13,18]$. Dimbylow reports that multiplying electric conductivity by a factor of 2 causes approximately $30 \%$ differences in $\mathrm{E}_{\mathrm{in}}$ values in the brain [18]. Available dielectric properties of body tissues were determined mainly for EMF frequencies above $1 \mathrm{MHz}$ by using the dispersion model [22]. The applicability of this model in the low frequency range is limited, so the dielectric properties of human body tissues should be used carefully.

\section{Posture and height}

Almost all the discussed virtual phantoms represent humans in a standing posture (Table 2). This fixed posture is a limitation in relation to flexible ones, because the distribution of local EMF energy absorption in particular body parts is related to the human body posture. The author's investigations show up to 36 times higher SAR in models in a realistic sitting posture in comparison to an unrealistic standing one [13]. The worker is usually close to the EMF source in different postures, and for such cases flexible phantoms should be preferred, even when they are homogenous only [13]. In fact, flexible phantoms are of limited availability, as discussed earlier.

The human body phantoms presented in Table 2 have differing heights and structures. All the phantoms, except for child phantoms and High Fidelity Male Body Mesh, are in the range of $1.76 \mathrm{~m} \pm 8 \%(1.62-1.90 \mathrm{~m})$ in height, as required by EN 50505:2008, but $\mathrm{E}_{\text {in }}$ and SAR values obtained for such phantoms are significantly differing: up to $20 \%$ differences in $\mathrm{E}_{\text {in }}$ in the brain of phantoms of 163 and $176 \mathrm{~cm}$ height exposed to homogenous EMF of $50 \mathrm{~Hz}$ [18], and up to 2 times differences between SAR values in phantoms of 160 and $186 \mathrm{~cm}$ height [29]. 


\section{Insulating/grounding conditions}

The next key issue in an exposure assessment of workers exposed to an electric field is insulating conditions $[18,19]$. Anatomically-based phantoms have a different number of voxels in contact with the ground (which may be assumed as an area of electric grounding). For example, some phantoms look like they are standing on their toes and have only a few voxels in contact with the ground, due to which such phantoms may not adequately represent the electric field exposure effects.

A grounded phantom represents the worst-case scenario of exposure to electric fields and, for example, internal electric fields or SAR values are significantly higher in relation to values obtained in insulated phantoms - reported up to 12 times differences between SAR values $[13,18]$. Therefore, it is important to determine precisely how large portion of the surface of the human body phantom is grounded in order to obtain reliable simulation results [13]. This issue has not yet been standardised and is irrelevant in magnetic field exposure assessments.

\section{Spatial resolution}

The phantoms used in simulations have various resolutions. In simple words, the highest resolution (more detailed) models give more reliable results, but also need more precise medical data to be developed and significantly higher computing power to be used in simulations $[18,43]$. The use of high resolution human body phantoms may lead to very long calculation times, e.g., exceeding several hundred hours [41] and needs a large amount of random access memory (RAM) and a high computing power of workstations (e.g., the XFdtd software needs 30 bytes of RAM for each voxel [38] and the Hugo human body phantom consists of approximately 10 million voxels at a $2 \times 2 \times 2 \mathrm{~mm}^{3}$ resolution, and approximately 700 thousand at $\left.5 \times 5 \times 5 \mathrm{~mm}^{3}[32]\right)$.

However, that very high resolution may fail to improve simulations, for example Dimbylow [18] concludes that there is no significant difference among localised internal electric field values obtained from EMF exposure assessments calculated for human body phantoms of $2 \times 2 \times 2 \mathrm{~mm}^{3}$ and of $1 \times 1 \times 1 \mathrm{~mm}^{3}$. An evaluation of $E_{\text {in }}$ or SAR values over a specified volume or mass may be not available with the use of some anatomical phantoms, because of their differing resolutions and tissue densities [13].

Taking all of these issues into account, a reference human body phantom resolution should be defined by developing a standardised protocol of compliance testing to ensure comparable results from various laboratories using EMF simulations in testing compliance of exposure conditions with the provisions of Directive 2013/35/EU [5].

\section{CONCLUSIONS}

The outcome from the presented examination of virtual phantoms used in numerical simulations shows that they can be effectively used in compliance assessment against the exposure limits specified by Directive 2013/35/EU [5], but various limitations still exist and phantoms continue to be improved. These limitations mainly involve the posture, insulating conditions or spatial resolution of virtual phantoms. A great number of those phantoms represent the human body in a standing posture, whereas, especially in the case of localised $E_{\text {in }}$ or SAR evaluation, flexibility in the phantoms' postures is required, because an unrealistic posture can greatly under- or overestimate exposure assessment. A multiple under- or overestimation of exposure assessment can also be a result of the phantom's unrealistic contact with the ground - mainly related to a limited contact surface (e.g., a few square centimetres), which is important especially in electric field exposure assessments. It should be noted that a coarse resolution of virtual phantoms can be insufficient to evaluate $\mathrm{E}_{\text {in }}$ or SAR values over volume or mass specified in guidelines.

The discussed usefulness and limitations related to human body phantoms should be considered, and specified, 
or perhaps standardised to obtain reliable results in the analysis of compliance with Directive 2013/35/EU [5] exposure limits, and may improve protection of workers against harmful EMF exposures. Such processes should also consider computing power and simulation time requirements related to the practical use of numerical simulations in EMF exposure assessments.

\section{REFERENCES}

1. Reilly PJ. Applied bioelectricity. From electrical stimulation to electropathology. New York: Springer-Verlag; 1998, http:/ dx.doi.org/10.1007/978-1-4612-1664-3.

2. International Commission on Non-Ionizing Radiation Protection (ICNIRP). Guidelines for limiting exposure to timevarying electric, magnetic, and electromagnetic fields (up to $300 \mathrm{GHz}$ ). Health Phys. 1998;74(4):494-522.

3. International Commission on Non-Ionizing Radiation Protection (ICNIRP). Guidelines for limiting exposure to timevarying electric and magnetic fields $(1 \mathrm{~Hz}-100 \mathrm{kHz})$. Health Phys. 2010;99(6):818-36.

4. Gryz K, Karpowicz J, Hietanen M. EU Directive, ICNIRP guidelines and Polish legislation on electromagnetic fields. Int J Occup Saf Ergon. 2006;12(2):125-36, http://dx.doi.org/ 10.1080/10803548.2006.11076675.

5. Directive 2013/35/EU of the European Parliament and of the Council of 26 June 2013 on the minimum health and safety requirements regarding the exposure of workers to the risks arising from physical agents (electromagnetic fields) (20th individual Directive within the meaning of Article 16(1) of Directive 89/391/EEC), O.J. No. L-179 of 29 June 2013, Brussels, Belgium.

6. Nagaoka T, Watanabe S, Sakurai K, Kunieda E, Taki M, Yamanaka Y. Development of realistic high-resolution wholebody voxel models of Japanese adult males and females of average height and weight, and application of models to radio-frequency electromagnetic-field dosimetry. Phys Med Biol. 2004;49(1):1-15, http://dx.doi.org/10.1088/00319155/49/1/001.
7. Sandrini L, Vaccari A, Malacarne C, Cristoforetti L, Pontalti R. RF dosimetry: A comparison between power absorption of female and male numerical models from 0.1 to 4 GHz. Phys Med Biol. 2004;49(22):5185-201, http://dx.doi. org/10.1088/0031-9155/49/22/012.

8. Hadjem A, Lautru D, Wong MF, Fouad Hanna V, Wiart J. Study of specific absorption rate (SAR) induced in two child head models and in adult heads using mobile phones. IEEE Trans Microw Theory Tech. 2005;53(1):4-11, http://dx.doi.org/10.1109/TMTT.2004.839343.

9. Bernardi P, Cavagnaro M, Pisa S, Piuzzi E. On the development of compliance procedures for BTS antennas. Proceedings of the 8th Congress of The European Bioelectromagnetics Associacion (EBEA); 2007 Apr 11-13; Bordeaux, France, paper No. S-2-7.

10. Karpowicz J, Gryz K. Practical aspects of occupational EMF exposure assessment. Environmentalist. 2007;27:525-31, http://dx.doi.org/10.1007/s10669-007-9067-y.

11. Hansson Mild K, Alanko T, Gryz K, Hietanen M, Karpowicz J, Decat G, et al. Exposure of workers to electromagnetic fields. A review of open questions on exposure assessment techniques. Int J Occup Saf Ergon. 2009;15(1):3-33.

12. Jokela K. Assessment of complex EMF exposure situations including inhomogeneous field distribution. Health Phys. 2007;92:531-40, http://dx.doi.org/10.1097/01.HP.0000 250620.32459.4c.

13. Zradziński P. Difficulties in applying numerical simulations to an evaluation of occupational hazards caused by electromagnetic fields. Int J Occup Saf Ergon. Forthcoming 2015.

14. Gedliczka A. [Atlas of human body measures - Data sheets for ergonomic and evaluation]. Warszawa: Central Institute for Labour Protection; 2001. Polish.

15. ErgoDesign. Electronic database of anthropometric and biomechanics data. Institute of Industrial Design; 2000.

16. International Commission on Radiological Protection. Basic anatomical and physiological data for the use in radiological protection: Reference values. ICRP publication 89. Ann ICRP. 2002;32(3-4). 
17. Gabriel C. Compilation of the dielectric properties of body tissues at RF and microwave frequencies. Brooks Air Force Technical Report AL/OE-TR-1996-0037 [cited 2014 Mar 25]. Available from: http://niremf.ifac.cnr.it/docs/DIELECTRIC/Report.html.

18. Dimbylow PJ. Development of the female voxel phantom, NAOMI, and its application to calculations of induced current densities and electric fields from applied low frequency magnetic and electric fields. Phys Med Biol. 2005;50(6): 1047-70, http://dx.doi.org/10.1088/0031-9155/50/6/002.

19. Gandhi OP, Chen JY. Numerical dosimetry at the powerline frequencies using anatomically based models. Bioelectromagnetics. 1992;Suppl. 1:43-60, http://dx.doi.org/10.1002/ bem. 2250130706 .

20. European Committee for Electrotechnical Standardization (CENELEC). Basic standard for the evaluation of human exposure to electromagnetic fields from equipment for resistance welding and allied processes (EN 50505:2008). Brussels: CENELEC; 2008.

21. Hagman MJ, Gandhi OP. Numerical calculation of electromagnetic energy deposition in models of man with grounding and reflector effects. Radio Sci. 1979;14(6S):23-9, http:// dx.doi.org/10.1029/RS014i06Sp00023.

22. Rehman M, Alfadhl Y, Wang Z, Chen X, Tattersall J, Inns R. Study of human body exposure to RF signal at UHF frequencies. Proceedings of the BioEM2009; 2009 Jun 14-19; Davos, Switzerland. Davos: Curan Associates; 2009. p. 505-7.

23. National Radiological Protection Board. Review of the scientific evidence for limiting exposure to electromagnetic fields (0-300 GHz). Doc NRPB. 2004;15(3):1-224.

24. Wiart J, Conil E, El Habachi A, Hadjem A, Gati A, Wong MF. Analysis of the influence of the body surface area on the power absorbed by human body exposed to a plane wave at $2100 \mathrm{MHz}$. Proceedings of the BioEM2009; 2009 Jun 14-19; Davos, Switzerland. Davos: Curan Associates; 2009. p. 63-5.

25. Ferrari P, Gualdrini G. An improved MCNP version of the NORMAN voxel phantom for dosimetry studies. Phys Med Biol. 2005;50(18):4299-316, http://dx.doi. org/10.1088/0031-9155/50/18/005.

26. Zankl M, Fill U, Petoussi-Henss N, Regulla D. Organ dose conversion coefficients for external photon irradiation of male and female voxel models. Phys Med Biol. 2002;47(14):2367-85, http://dx.doi.org/10.1088/00319155/47/14/301.

27. Zankl M, Wittmann A. The adult male voxel model "Golem" segmented from whole-body CT patient data. Radiat Environ Biophys. 2001;40:153-62, http://dx.doi.org/10.1007/ s004110100094.

28. U.S. National Library of Medicine. The Visible Human Project [cited 2014 Apr 25]. Available from: http://www.nlm.nih. gov/research/visible/visible_human.html.

29. Conil E, Hadjem A, Lacroux F, Wong MF, Wiart J. Variability analysis of SAR from $20 \mathrm{MHz}$ to $2.4 \mathrm{GHz}$ for different adult and child models using finite-difference timedomain. Phys Med Biol. 2008;53(6):1511-25, http://dx.doi. org/10.1088/0031-9155/53/6/001.

30. Xu XG, Chao TC, Bozkurt A. VIP-Man: An image-based whole-body adult male model constructed from color photographs of the Visible Human Project for multi-particle Monte Carlo calculations. Health Phys. 2000;78(5):476-86, http://dx.doi.org/10.1097/00004032-200005000-00003.

31. Speag.com [Internet] [cited 2014 Mar 25]. Available from: http://www.semcad.com.

32. Cst.com [Internet]. Computer simulation technology [cited 2014 Mar 25]. Available from: http://cst.com.

33. Lee C, Lee C, Lee J. Korean adult male voxel model KORMAN segmented from magnetic resonance image. Med Phys. 2004;31(5):1017-22, http://dx.doi.org/10.1118/ 1.1689013.

34. Lee C, Lee C, Park S, Lee J. Development of the 2 Korean adult tomographic computational phantoms for organ dosimetry. Med Phys. 2006;33(2):380-90, http://dx.doi. org/10.1118/1.2161405.

35. El Habachi A, Conil E, Hadjem A, Vazquez E, Wong MF, Gati A, et al. Statistical analysis of whole-body absorption 
depending on anatomical human characteristics at a frequency of $2.1 \mathrm{GHz}$. Phys Med Biol. 2010;55(7):1875-87, http://dx.doi.org/10.1088/0031-9155/55/7/006.

36. Kramer R, Vieira JW, Khoury HJ, Lima FR, Fuelle D. All about MAX: A Male Adult voXel phantom for Monte Carlo calculations in radiation protection dosimetry. Phys Med Biol. 2003;48(10):1239-62, http://dx.doi.org/10.1088/00319155/48/10/301.

37. Kramer R, Khoury HJ, Vieira JW, Loureiro ECM, Lima VJM, Lima FRA, et al. All about FAX: A Female Adult voXel phantom for Monte Carlo calculation in radiation protection dosimetry. Phys Med Biol. 2004;49(23):5203-16, http://dx.doi.org/10.1088/0031-9155/49/23/001.

38. Remcom.com [Internet]. Electromagnetic Simulation Software [cited 2014 Mar 25]. Available from: http://rem com.com.

39. Christ A, Kainz W, Hahn EG, Honegger K, Zefferer M, Neufeld E, et al. The Virtual Family - Development of anatomical CAD models of 2 adults and 2 children for dosimetric simulations. Phys Med Biol. 2010;55(2):N23-38, http://dx.doi.org/10.1088/0031-9155/55/2/N01.

40. Itis.ethz.ch [Internet]. ITIS Foundation [cited 2014 Mar 25]. Available from: http:/www.itis.ethz.ch/services/anatomicalmodels/virtual-population.

41. Zradziński P. [The modeling and evaluation of the exposure of the workers operating suspended resistance welders to the simultaneous electromagnetic and biomechanical factors]. Acta Biooptica Inf Med. 2012;18(1):50-4. Polish.

42. Zradziński P. The properties of human body phantoms used in calculations of electromagnetic fields exposure by wireless communication handsets or hand-operated industrial devices. Electromag Biol Med. 2013;32(2):226-35, http://dx.doi. org/10.3109/15368378.2013.776434.

43. Gandhi OP. Electromagnetic fields: Human safety issues. Ann Rev Biomed Eng. 2002;4:211-34, http://dx.doi. org/10.1146/annurev.bioeng.4.020702.153447.

This work is available in Open Access model and licensed under a Creative Commons Attribution-NonCommercial 3.0 Poland License - http://creativecommons.org/ licenses/by-nc/3.0/pl/deed.en. 